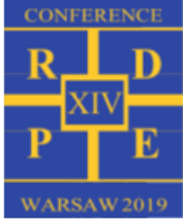

\title{
Experimental and numerical tip leakage flow visualization in the LP turbine labyrinth seal
}

\author{
Krzysztof B ochon ${ }^{1,}{ }^{*}$, Włodzimierz Wróblewski ${ }^{1}$, Artur Szymański ${ }^{1}$, Mirosław M ajkut ${ }^{1}$, Michat Strozik ${ }^{1}$ and Krzysztof \\ M arugi $^{2}$ \\ ${ }^{1}$ Silesian University of Technology - Institute of Power Engineering and Turbomachinery, K onarskiego18, 44-100 Gliwice, Poland, \\ krzysztof.bochon@polsl.pl \\ ${ }^{2}$ A vio A ero, Grażyńskiego 141 43-300 Bielsko-Biała, Poland
}

\begin{abstract}
The subject of this publication is the identification of basic flow parameters and flow structures in the seal experimentally and compare them with CFD results. A straight-through seal with two leaning fins and smooth or honeycomb land was analysed. The sealing concept is characteristic for the tip seal of the last stage of an aircraft low-pressure turbine. Due to the limitations of the test rig the analyses presented here were conducted on a highly simplified, stationary model of the seal itself, with an axial inflow and no curvature in the circumferential direction. The characteristics of the discharge coefficient as a function of the pressure ratio for different clearances and the pressure distribution al ong the seal, for different pressure ratios are presented. In addition, an attempt was made to visualize the flow using the schlieren technique. The main idea of application schlieren photography was to observe the vortex and separation structures occurring during the flow through the labyrinth seal, which is the major source of pressure losses. CFD calculations were carried out using the A nsys CFX commercial code.
\end{abstract}

\section{Introduction}

Ever increasing demand for high efficiency and low emission solutions in aerospace enforces significant efforts on engineers and scientists. Perfecting the aeroengine compartments is one of the areas with a significant impact on turbomachinery performance. Research by Rosic \& Denton [1] shows $2 \%$ of turbine efficiency drop due to internal leakages. The labyrinth seals are the most popular solution to eliminate or regulate the leakage in aero-engines. Despite the fact that state-of-the-art sealing solutions such as brush seals or finger seals reduce leakage much better [2], labyrinth seals are favoured mostly due to resistance to high temperature, highpressure ratios, high speed, rubbing and solid particles contamination [3]. Historically, a significant effort in labyrinth seals evaluation, including experiments [4-6], CFD calculations [7-10] and analytical methods [11-13] have been presented in the literature. The research to evaluate and assess labyrinth seals works has been going on since the 1970s when Detroit Diesel A llison performed some of the first experimental campaigns [14]. The first CFD calculations were performed $[15,16]$, using 2D models. Later on, 3D models were applied for various sealing solutions, with recently deployed LES methods $[17,18]$. Recently labyrinth seals are often applied with hole-patterns against it, for instance, honeycomb. Holepatterns cause some difficulties in mesh generation, hence the ideas for simplifying these structures during the numerical modelling. In [19] the honeycomb structure was replaced by square holes, to simplify the geometry, and lower the computational cost during optimization.
The most popular parameter used for the seal performance evaluation is the discharge coefficient $C_{D}$ :

$$
C_{D}=\frac{\dot{m}}{\dot{m}_{\text {ideal }}}
$$

defined as the ratio of mass flow occurring in the seal to $m_{\text {ideal, }}$ a theoretical isentropic flow through the clearance described by the relation for an isentropic flow through a nozzle:

$$
\dot{m}_{\text {ideal }}=\frac{p_{0} A_{\text {nom }}}{\sqrt{T_{0}}} \sqrt{\frac{2 \kappa}{R(\kappa-1)}\left[\left(\frac{1}{\pi}\right)^{2 / \kappa}-\left(\frac{1}{\pi}\right)^{(\kappa+1) / \kappa}\right]}
$$

The leakage highly depends on clearance size, and flow direction.

The studies presented here were a part of the research of the rotor tip seal of the low-pressure part of an aircraft engine turbine. Some parts of the research were described in [20-23]. The main goal of the research was to improve the efficiency of the analysed seal. Works within the research included numerous experimental studies and CFD analyses. In the part of the research, which is the subject of this publication, the focus was on the identification of the main flow parameters and flow structures in the seal on the test rig using the schlieren technique and comparison of the obtained results with the results of CFD analyses. The flow field and discharge characteristics were evaluated utilising commercial CFD tools, such as A NSY S CFX and the in-house experiment. 


\section{Methodology}

\subsection{Investigated geometries}

The seal analysed in this paper is a straight-through configuration with two fins. The labyrinth with smooth land (Fig. 1a) and honeycomb land (Fig. 1b) was investigated. The fins are inclined towards the inflow. The dimensions of the labyrinth as well as of the land structure can be found in [22].

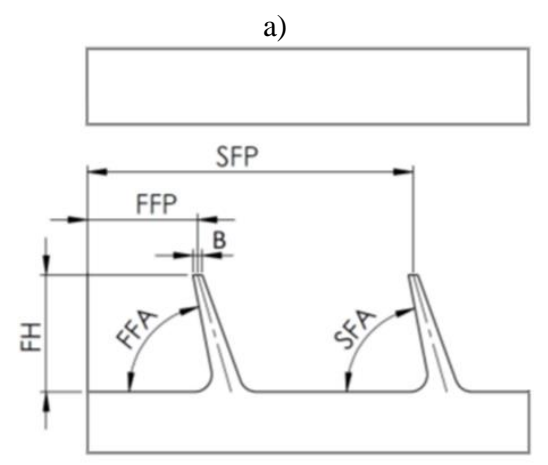

b)

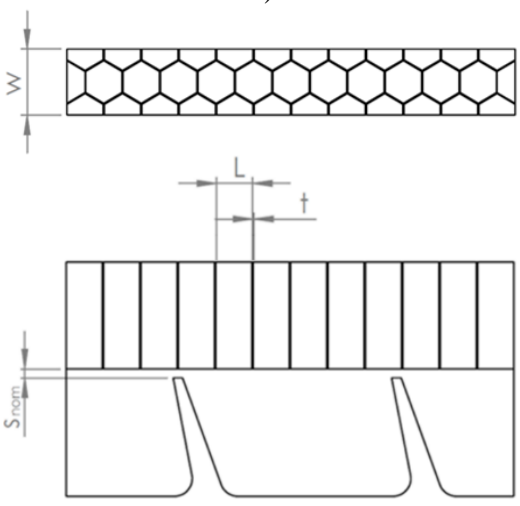

Fig. 1 Investigated sealing configurations: a) labyrinth with smooth land, b) labyrinth with honeycomb.

The analysed labyrinth configurations included a variety of load (pressure ratio) and clearance size, but the nominal operation point was for $\pi=1.16$ and clearance $s=0.75 \mathrm{~mm}$.

\subsection{General computational approach}

The numerical simulations for presented in Fig. 1 configurations were performed using the ANSYS CFX code. The numerical study presented in the paper focuses on the sealing structure only. The other structures commonly present together with the seals, such as inlet and outlet cavities are not evaluated here. The reason to simplify the computational domain was to keep it the same as in the experimental setup, where the inlet and outlet cavities are not taken into account.

A $n$ exemplary model of the labyrinth seal with facing is presented in Fig. 2. The width of the domain model is determined by land structure periodicity. For example, in the honeycomb land, the flow domain width is equal to two honeycomb cells. Therefore, the translational periodicity condition is assumed in the lateral areas of the computational domain. To obtain a uniform velocity profile at the inlet, an extra inlet channel is added to the seal area. B ecause a strong jet is formed downstream of the last fin clearance, causing a substantial disturbance to the outlet zone and creating large vortex structures, the outlet channel is also lengthened. At the ends of the channel extensions, the inlet and outlet boundary conditions are specified. Generally, the land area and the main channel (sealing, inlet and outlet channel) are prepared as separate domains because of the meshing strategy. A ppropriate surfaces of these domains are joined using the General Grid Interface method, which permits non-matching of the element node location. On the domain remaining surfaces (top and bottom ones and on the walls of the honeycomb cells) the adiabatic wall conditions are assumed. The mesh has been checked with respect to its sensitivity to the refinement. M ore details on the CFD approach applied to this problem was described in the paper [24].

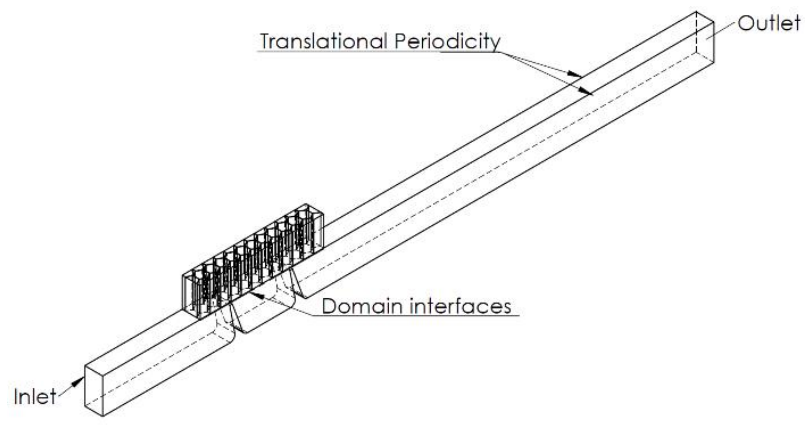

Fig. 2 Computational domain.

The flow is steady and adiabatic. The two-equation k$\omega$ SST turbulence model is chosen. The energy equation includes the viscous work term. The higher-order upwind advection scheme is selected to solve the governing equation system. Following boundary conditions were applied: inlet parameters were specified as total pressure and temperature $(101.325 \mathrm{kPa}, 288.2 \mathrm{~K})$, at a direction normal to the boundary. Walls were treated as adiabatic and smooth. Static pressure defined the outlet boundary condition, with the blend profile of 0.05 . It varied from 50 to $95 \mathrm{kPa}$. Air treated as an ideal gas, with Sutherland formula for viscosity change was the working fluid. The boundary condition at the outl et is the mean value of static pressure, which depends on the conditions of the seal operation. The labyrinth seal loading is evaluated by pressure ratio $\pi$ which is defined as:

$$
\pi=\frac{p_{0}}{p_{s}}
$$

where $p_{s}$ is outlet static pressure and $p_{0}$ is the inlet total pressure.

\subsection{Experimental approach}

The experiment was realised using a test section with a vacuum installation. A testing approach based on atmospheric air supply guarantees precise determination of stagnation parameters at the inlet section and no thermal deformation of a specimen. The static temperature during the test was in the range of $5-25^{\circ} \mathrm{C}$, 
which guaranteed unchangeable sizes of the clearance and constant shape of the fins. The vacuum in the system is generated using a Roots blower with the output of 12.4 $\mathrm{N} \mathrm{m3/min}$. The pressure vessel with the $3 \mathrm{~m}^{3}$ capacity compensates the pressure fluctuations and stabilises parameters downstream of the test section. On the test section side, the air is sucked in through a $4 \mathrm{~m}$ long inlet pipeline. In this point, first flow measurement is performed using the hot wire anemometry probe (HWA). $\mathrm{N}$ ext, the air flows through the test section. A fter the air leaves the testing section, it expands and gets into the outlet pipeline, where the second HW A probe and an ISA orifice plate are installed. The mass flow measurement applied in three points guarantees high accuracy of seal leakage determination. It also makes it possible to detect potential leaks in the installation.

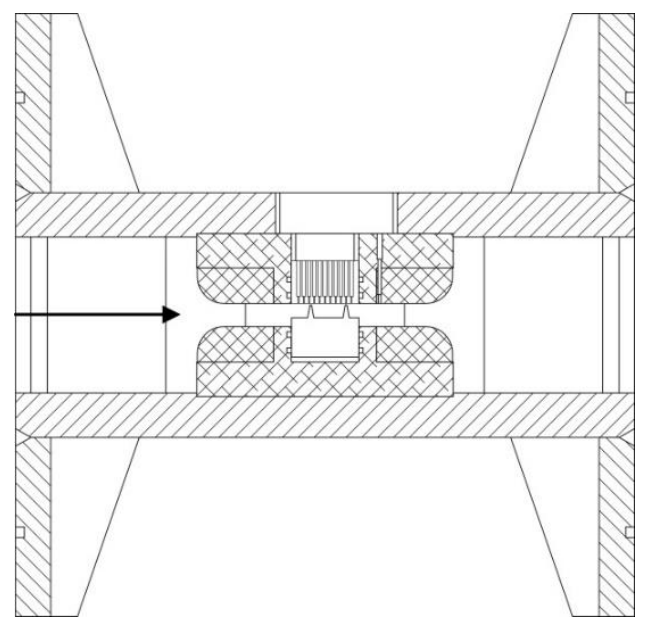

Fig. 3 Test rig cross-section.

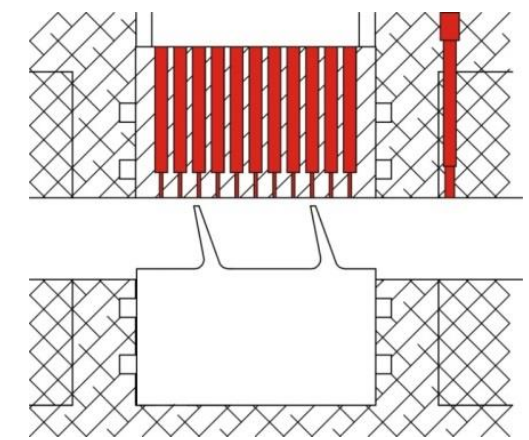

Fig. $4 \mathrm{~L}$ abyrinth and the facing specimen area with the holes for pressure measurements.

The cross-section of the rig shows its components, as presented in Fig. 3. A quasi-2D approach of the labyrinth seal was applied - stationary specimens were used without keeping the circumferential curvature. As proved in previous works $[19,25]$, as well as from own experience, this approach ensures adequate accuracy in determining flow parameters. It can also be related successfully to axially symmetrical geometries. The results of the experimental works $[26,27]$ proved that a stationary configuration can be used with great accuracy if the flow velocity over the labyrinth fin is higher than the rotor tangential velocity in the labyrinth area $\left(u / c_{a x}<\right.$ 1 condition is satisfied) which in practice concerns the aero-engine low-pressure turbines as well as heavy-duty turbines because of a relatively low rotational speed.

A part from determining leakage for a given structure, the test rig also enables the measurement of the air pressure distribution al ong the labyrinth seal, as presented in Fig. 4. In every case, there are $10-12$ points in every labyrinthfacing specimen where the static pressure value is measured. The pressure ratio $\pi$, defined by the formula (3), is calculated as ambient pressure divided by static pressure measured in the last pressure tap, downstream the labyrinth. The pressure ratio during CFD calculations was established in the same manner i.e. using the static pressure value from the location corresponding with the last pressure tap location. The width of the test rig is $240 \mathrm{~mm}$, what with clearances of $1 \mathrm{~mm}$ and less causes that the effect of the side walls boundary layer is negligible. The model adopted for the CFD study differs insignificantly when compared with the geometry deployed in the experiment. There is a small step before the labyrinth Fig. 4, which is a result of the need to regulate the clearance and is very small in relation to the height of the entire channel. The step is located in the bottom part of the channel, which, as it appeared from previous experience, has a negligible effect on the flow in the seal, because the jet flowing on the first fin is formed continuously before the clearance. The influence of the inlet nozzle location and its shape was numerically examined at the design stage of the test rig. The change of $C_{D}$ value was lower than $0.2 \%$ and therefore neglected.

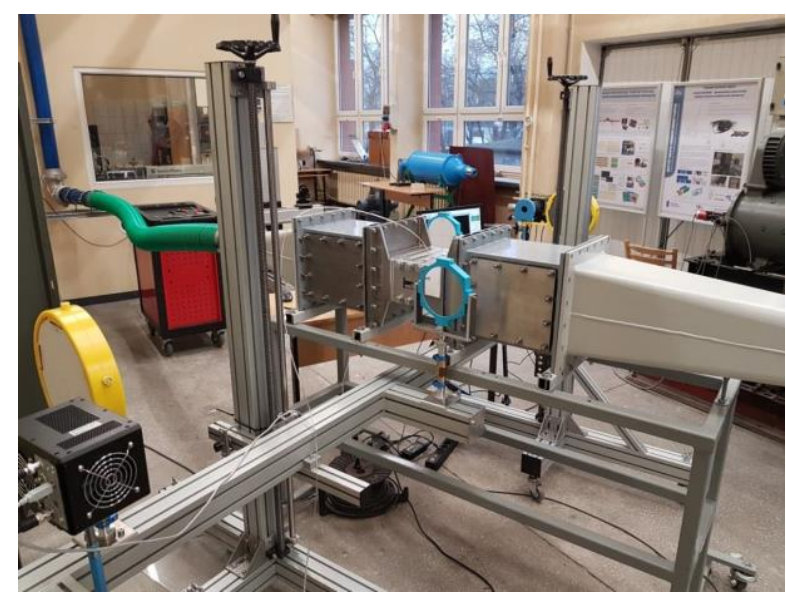

Fig. 5 Test section with schlieren apparatus.

\subsection{Schlieren optical flow field measurement}

Apart from the mass flow characteristics and pressure distribution along the seal, the test section brings about the flow field visualisation with schlieren technique. The standard implementation of a schlieren system uses light from a single collimated source shining on, or from behind, a target object, lens, schlieren knife and receiver camera. Variations in refractive index caused by density gradients in the flowing fluid distort the collimated light beam. This distortion creates a spatial variation in the intensity of the light, which can be visualized directly with a shadowgraph system. The main advantage of this method is its non-invasive idea, short time of measurement and simplicity. Fast Speed Camera Phantom 
Miro C110 has been deployed to capture the flow field. It achieves up to 800 frames-per-second (fps) at full 1.3 Mpx resolution of $1280 \times 1024$, and up to over $29,800 \mathrm{fps}$ at smaller resolutions. In this case, the light source was NANOLITE Nanosecond-Flash lamps. The main idea of application schlieren photography was to observe the vortex and separation structures occurring during the flow through the labyrinth seal, which is the major source of pressure losses. Fig. 5 presents an overview of the schlieren installation in the laboratory and Fig. 6 shows the schlieren setup used for the presented study.

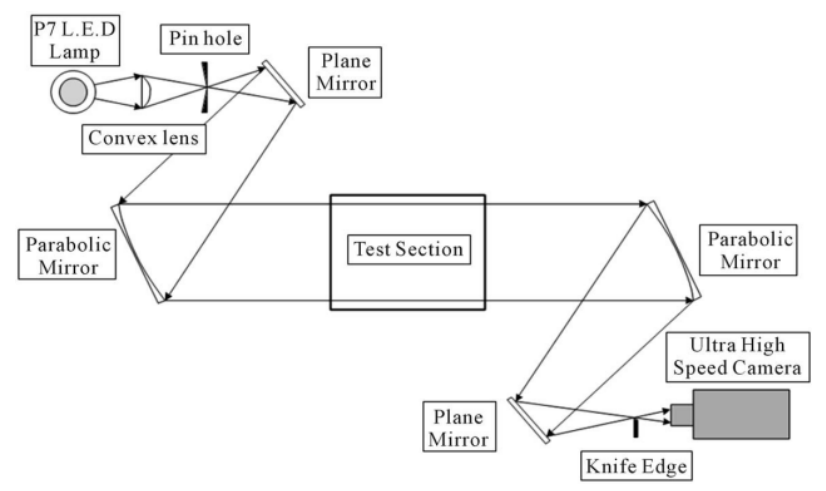

Fig. 6 Schlieren setup scheme.

For the sake of comparison, so-called 'numerical schlieren' results based on the CFD simulations were compared with the experiment. The numerical schlieren is defined as the absolute value of the density gradient on the planar cross section in the flow domain.

Comparison of results for experimental and numerical schlieren for honeycomb land raises some problems. The point is that with this type of land, the flow structure is not uniform in the circumferential direction and changes with the change in the relationship of the honeycomb cell's position and the sealing fin. It means that the jets behind the seal fins and the swirls in the seal chambers will look differently in different cross-sections in the circumferential direction. This will also apply to the density gradient and thus what we see in the images presenting for the schlieren results. In the case of numerical schlieren, the presented results show the distribution of the density gradient in a specific crosssection. In the case of an experiment, the presented image is the result of the refraction of light in subsequent layers of fluid along the entire width of the measuring chamber.

Detailed comparison of obtained images and extracting specific conclusions from them is very difficult and unjustified in this situation. Therefore, the schlieren results presented in the paper are aimed at a very general analysis of emerging structures, observing certain trends and relating them to the numerical results presented in selected axial cross-sections of the seal.

\section{Results}

\subsection{Seal with Smooth land}

The $C_{D}$ value for the nominal conditions obtained from CFD simulations amounts to $C_{D}=0.589$. The agreement of CFD with experimental results is substantial (Fig. 7).
The result indicates the linear character of changes of the $C_{D}$ with pressure ratio and clearance.

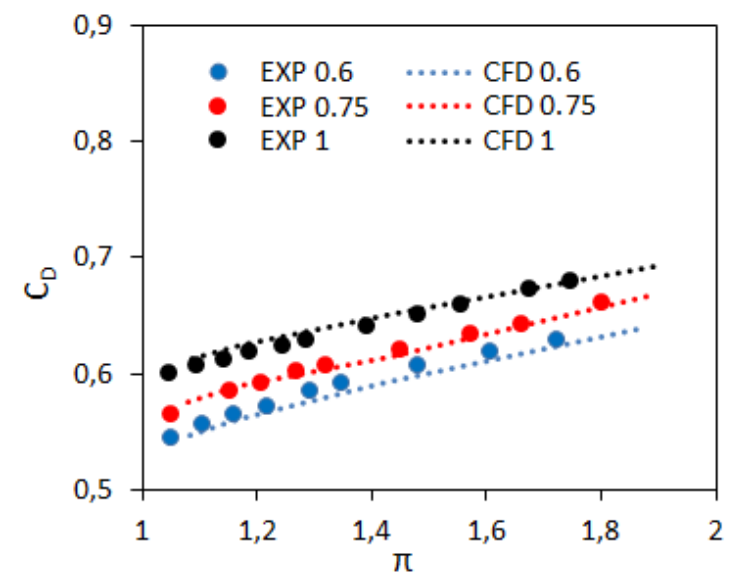

Fig. 7 Labyrinth seal with smooth land - experimental and numerical discharge coefficient in function of pressure ratio.

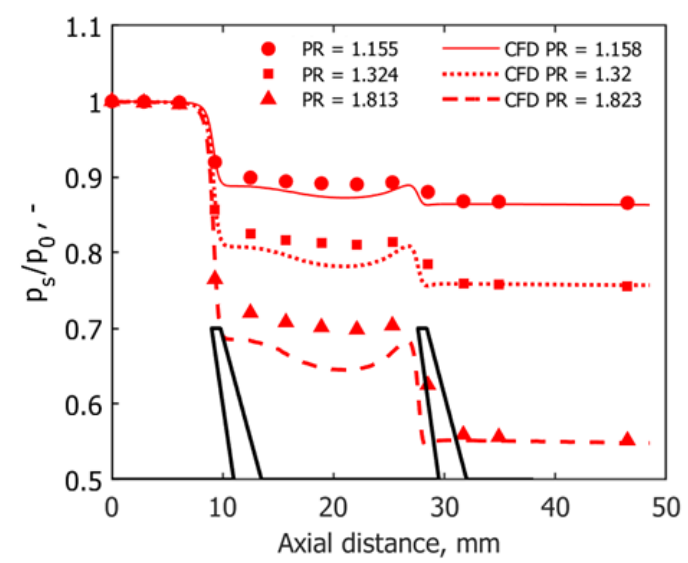

Fig. 8 Experimental and numerical static pressure distribution - labyrinth against smooth land, clearance $s=0.75 \mathrm{~mm}$

The pressure distributions for different pressure ratios along the seal are depicted in Fig. 8. The distributions indicate the regions responsible for pressure loss, which is the major mechanism responsible for leakage limitation. They also suggest possible velocities in the cavity and carryover effect. Presented results combine computed and measured pressure distributions. The pressure distributions are shown on the example of a 0.75 $\mathrm{mm}$ clearance. The highest pressure drop is always observed at the first fin. When the pressure ratio rises, the second fin contribution in pressure loss generation is more significant. For clearances of 0.6 and $1 \mathrm{~mm}$ the distribution looks very similar, the main difference is that as the clearance decreases, the pressure drop on the first fin increases and decreases on the second fin. Overall, the contribution of the second fin is lower than $10 \%$ of total pressure drop for low pressure ratios $(\pi<1.15)$, and reaches up to $33 \%(s=0.75 \mathrm{~mm})$ and $18 \%(s=1 \mathrm{~mm})$ at high pressure ratios $\pi \approx 1.8$, respectively. This means that the carry-over effect increases with the increase of the clearance and Reynolds number.

The experimental and CFD flow visualisation of reference and optimised labyrinth seal is presented in Fig. 9. The figures indicate the density gradient maps at two values of pressure ratio - low (1.16) and high (1.8), for 
the clearance of $0.75 \mathrm{~mm}$. The same range of parameter was applied to the results presented in the next case. Therefore, some difference may be spotted, i.e. the experiments do not show the circular vortexes between the fins or downstream the second one. The CFD calculations predict the circular one, while the experiment shows significantly stochastic behaviour. Both methods predicted strong bottom vortex in front of the first fin, having a similar shape for both pressure ratios. Both methods predicted expanding jet angle downstream the labyrinth fin tips - which shows the place of higher velocity and density change. The effect is stronger for high-pressure ratios, and the mentioned angle is wider.

a)

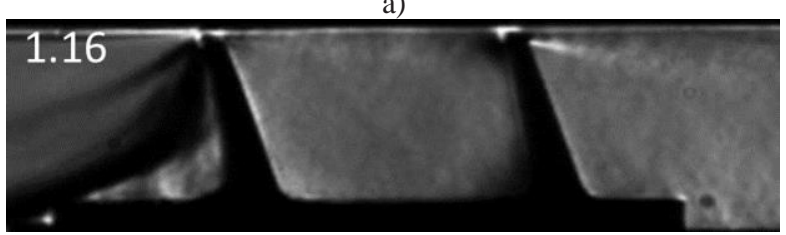

b)

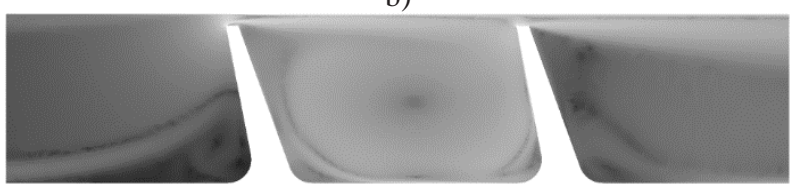

c)

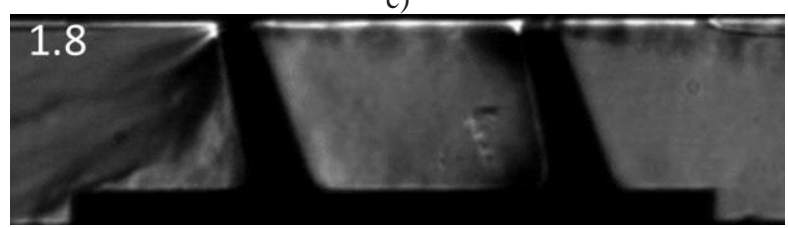

d)

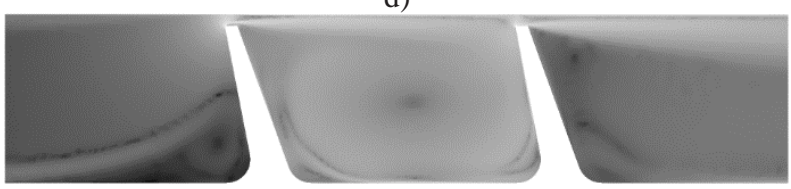

Fig. 9 Experimental a), c) and numerical b), d) schlieren pictures for labyrinth with smooth land, at low (1.16) a), b) and high (1.8) c), d) pressure ratios, clearance $s=0.75 \mathrm{~mm}$

\subsection{Seal with honeycomb land}

The $C_{D}$ value for the nominal conditions for the honeycomb case amounts to 0.590 . The experimental results of the discharge coefficient distributions with pressure ratio match well with the numerically predicted data (Fig. 10). Slightly larger difference can be observed only for the clearance of 0.75 . The honeycomb case results reveal ed behaviour specific for labyrinth seals with cell structures - the discharge coefficient depends highly on clearance size. It is higher for low clearances and reduces with the clearance rise. This behaviour is opposite to trends observed in the configuration with smooth land. Similar behaviour was previously indicated by Alizadeh [9], where the $C_{D}$ raised by $40-50 \%$ after application of honeycomb on the labyrinth seal with three straight fins. The mechanism was also extensively described by Schramm [28], where the experimental results presented even $65 \%$ increase of leakage after the honeycomb was applied. This experience shows that using honeycomb may have a negative effect on the mass flow rate.

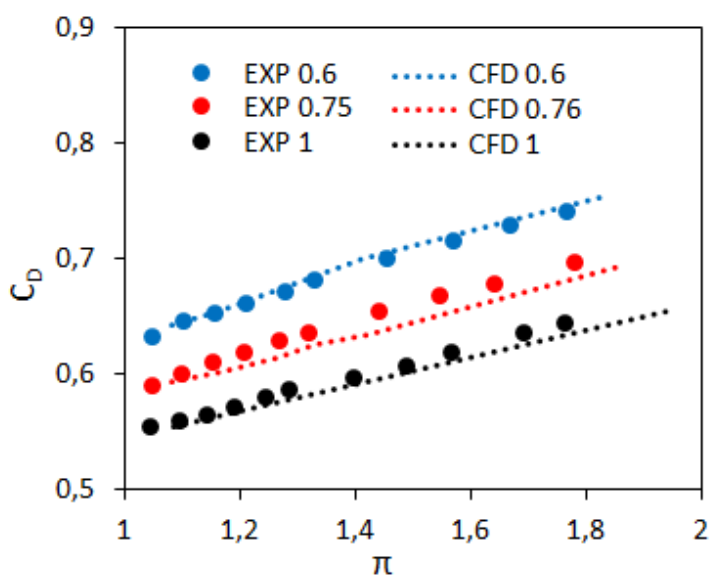

Fig. $10 \mathrm{~L}$ abyrinth seal with honeycomb land - experimental and numerical discharge coefficient in function of pressure ratio.

The comparison of experimental and CFD results for pressure distribution in the seal for clearance $0.75 \mathrm{~mm}$ is depicted in Fig. 11 for different pressure ratios. The computed results are collected from the top part of the honeycomb land to be in agreement with the positions of the pressure probes. Therefore, the lines of the pressure distribution have characteristic step-like shape, which reflects different pressure levels in the honeycomb cells. In contrast to seal with the smooth land, here with honeycomb land, the second fin plays a more important role in pressure loss mechanism and leakage limitations. The pressure drop on the second fin is around of $50 \%$ of the overall pressure drop in the seal.

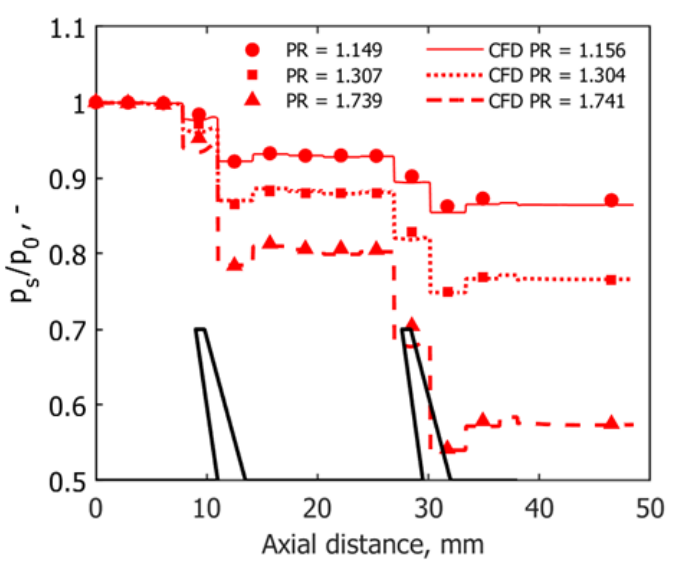

Fig. 11 Experimental and numerical static pressure distribution - labyrinth against honeycomb land, clearance $s=0.75 \mathrm{~mm}$.

The shape of pressure distribution in the case of honeycomb land differs from the smooth case. The damping effects of the honeycomb are clearly visible. M oreover, the pressure drop in the area just behind fin tips indicates locally lower pressure values than in area downstream fin tips. The mentioned area corresponds to the honeycomb cell, in which the pressure prevails. The pressure above the fin can be substantially lower than in area downstream of the labyrinth, especially for the higher pressure ratios. The agreement of CFD results with 
pressure ratio experiment was substantial (Fig. 11). Due to much lower jet velocity, the RANS model predictions were more appropriate than in the structure with smooth land.

a)

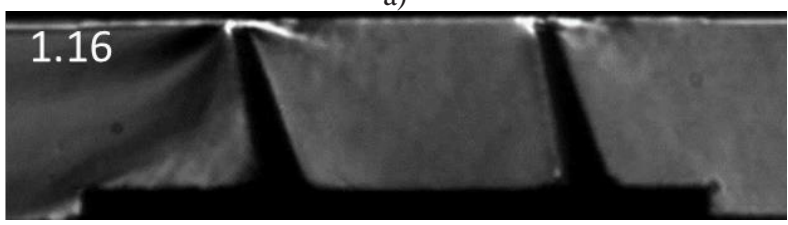

b)

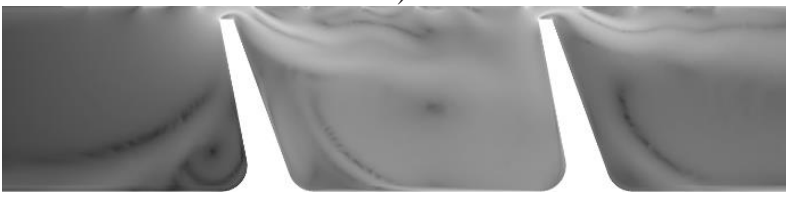

middle plane

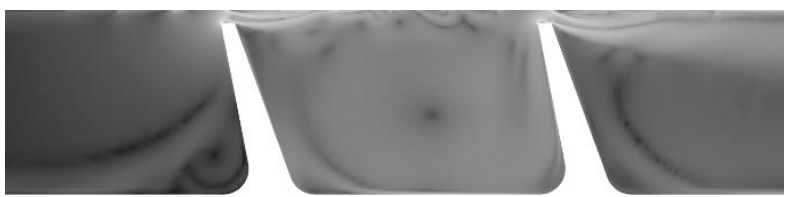

side plane

c)

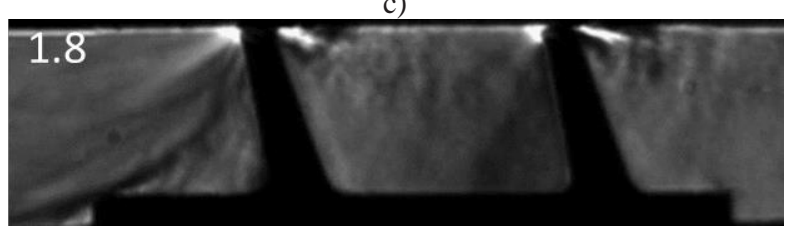

d)

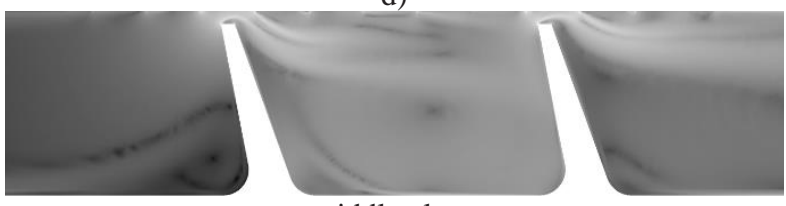

middle plane

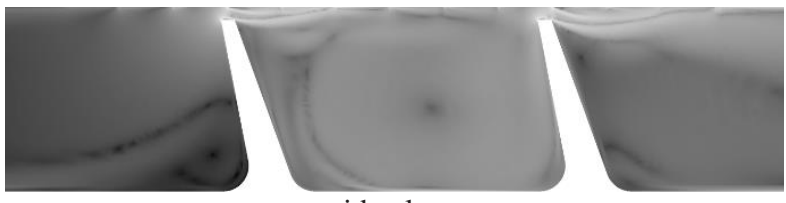

side plane

Fig. 12 Experimental a), c) and numerical b), d) schlieren pictures for labyrinth with honeycomb land, at low (1.16) a), b) and high $(1.8) \mathrm{c}$ ), d) pressure ratios, clearance $\mathrm{s}=0.75 \mathrm{~mm}$.

Fig. 12 shows the schlieren and CFD flow visualisation of the labyrinth seal with honeycomb land. Similarly, as in the smooth land case the schlieren photograph presented instantaneous flow field, therefore, some of the time-averaged flow field features may not be visible. As it was explained earlier the schlieren photographs reflect the changes in the flow structure extended al ong the width of the labyrinth specimen $(240 \mathrm{~mm})$, in contrast, the numerical schlieren presents the values calculated on the plane. Therefore, numerical schlieren views for every case are represented on two planes. One is located in the middle of the computational domain and the second on the side of the domain. Generally, both planes intersect the honeycomb structure in the middle of cells but the cells are shifted by a half of the cell size in both planes.
Also in the area after the second fin, the flow is highly turbulent. The eddy's shape after the second fin depends on the pressure ratio and reverses at high loads. This reversal flow has an adverse effect on the leakage amount, which is noticeable due to relatively low leakage at high loads, previously indicated in Fig. 10. The experimental schlieren presents much stronger turbulent structures in front of the first fin. In addition, the effects of high value of pressure ratio can be noted, with the air density shadows originating from the trailing edge of the fins. It is noticeable, that due to the honeycomb structure the inclination of the jets just behind fins take place. The jets are headed towards the central part of the cavity, which enables stronger dissipation of kinetic energy.

\section{Discussions and conclusions}

The characteristics of the discharge coefficient as a function of the pressure ratio for different clearances and the pressure distribution along the seal, for different pressure ratios were presented. Important part was also the flow visualization using schlieren technique. Numerical and experimental investigations were performed for straight-through seal with two leaning fins and smooth or honeycomb land.

The agreement of CFD with experimental results is good concerning discharge coefficient parameter. The result indicates the linear character of changes of the $C_{D}$ with pressure ratio and clearance. The value of the discharge coefficient increases as the pressure ratio increases. In addition, in the case of a smooth land, the $C_{D}$ value increases as the gap increases. However, in the case of the honeycomb land, the situation is reversed, the smaller the clearance, the larger the $C_{D}$.

When it comes to pressure distributions, better agreement of the numerical simulations with the experiment was obtained for the honeycomb. In the case of smooth land, a small share of the second fin was observed in the overall pressure drop in the seal, which indicates the importance of the carry over effect characteristic of straight-through seals. Honeycomb seems to eliminate this effect because the pressure drop is similar on both fins. Similar conclusions regarding the carry over effect can be drawn by analysing schlieren results. $B$ oth in the case of experimental and numerical tests, the jets behind the fins for a smooth land are arranged more horizontally, which enhance the carry over effect, while in the case of honeycomb they deflect downwards, which gives a positive effect.

Schlieren pictures helped to understand the flow behaviour better. The major difference between the schlieren imaging and the CFD schlieren pictures is the fact that schlieren spatially averages the flow field in the direction perpendicular to the flow direction, and shows instantaneous results. The computed by RANS model numerical schlieren shows time-averaged results in selected planar location, therefore some differences can be seen, but the overall flow structures ale similar.

This work was supported by the Polish National Centre for Research and Development and by Avio Polska within the Innolot Programme, Coopernik Project. 


\section{References}

1. Rosic B., Denton J.D. Control of Shroud Leakage Loss by Reducing Circumferential Mixing, $J$ Turbomach, Vol. 130(2), (2008).

2. Chupp R.E., Hendricks R.C., Lattime S.B., Steinetz B.M., Sealing in Turbomachinery, NASA Technical Report, NASA/TM-2006-214341, (2006).

3. Steinetz B.M., Hendricks R.C., Braun M.J., Turbomachine Sealing and Secondary Flows, Part 1-Review of Sealing Performance, Customer, Engine Designer, and Research Issues, NASA Technical Report, NASA/TM-2004-211991/Part1, (2004).

4. Kong X., Liu G., Liu Y., Zheng L., Experimental testing for the influences of rotation and tip clearance on the labyrinth seal in a compressor stator well, Aerosp Sci Technol, Vol. 71 pp. 556-567, (2017).

5. Zhang X., Li W., Zhang X., Wang X., Zhu Y., Chen H., Experimental and Numerical Investigations of Closed Radial Inflow Turbine With Labyrinth Seals, J Eng Gas Turbines Power, Vol. 140(10), (2018).

6. Murata K., Kamishita M., Matsumoto K., Kawashita R., Iwasaki M., Tokimasa Y., Validation of CFD Analysis Method for Seal Dynamic Coefficients With Various Labyrinth Seal Types, Proc ASME Turbo Expo 2018 Power Land, Sea Air, GT201875251, pp. 1-10, (2018).

7. Elebiary K., Jin H., Untaroiu A., Hayrapetiau V., Fu G., The Effects of Fluid Preswirl and Swirl Brakes Design on the Performance of Labyrinth Seals, J Eng Gas Turbines Power, Vol. 140(8), (2018).

8. Wasilczuk F., Kaczynski P., Szwaba R., Marugi K., Flaszynski P., Doerffer P., Leakage flow analysis in the gas turbine shroud gap, Aircr Eng Aerosp Technol, (2018).

9. Alizadeh M., Nikkhahi B., Farahani A.S., Fathi A., Numerical study on the effect of geometrical parameters on the labyrinth-honeycomb seal performance, Proc Inst Mech Eng Part G J Aerosp Eng, pp. 1-12, (2017).

10. Lin Z., Wang X., Yuan X., Shibukawa N., Noguchi $\mathrm{T}$., Investigation and improvement of the staggered labyrinth seal, Chinese J Mech Eng, Vol. 28, pp. 402408, (2015).

11. Cangioli F., Pennacchi P., Nettis L., Ciuchicchi L., Design and Analysis of CFD Experiments for the Development of Bulk-Flow Model for Staggered Labyrinth Seal, Int J Rotating Mach, Vol. 2018, pp. 1-16 (2018).

12. Zimmermann H., Wolff K.H., Comparison Between Empirical and Numerical Labyrinth Flow Correlations, Proc ASME 1987 International Gas Turbine Conference and Exhibition, 1987, pp. 1-6, (1987).

13. Zimmermann H., Wolff K.H., Air System Correlations Part 1: Labyrinth Seals. Proc Int Gas Turbine Aeroengine Congr Exhib, 98-GT-206, (1998).

14. Stocker H.L., Cox D.M., Holle G.F., Aerodynamic Performance of Conventional And Advanced Design
Labyrinth Seals With Solid-Smooth Abradable And Honeycomb Lands, NASA Technical Report, (1977).

15. Choi D-C., Rhode D.L., Development of a 2-D CFD Approach for Computing 3-D Honeycomb Labyrinth Leakage, Proc ASME Turbo Expo 2003 Power Land, Sea Air, GT2003-38238, pp. 965-975. (2003).

16. Wittig S., Schelling U., Kim S., Jacobsen K., Numerical Predictions and Measurements of Discharge Coefficients in Labyrinth Seals, Proc ASME 1987 International Gas Turbine Conference and Exhibition, 87-GT-188, (1987).

17. Tyacke J.C., Jefferson-Loveday R., Tucker P.G., Application of LES to labyrinth seals, Proc 20th AIAA Comput Fluid Dyn Conf, pp. 1-24, ( 2011).

18. Tyacke J., Jefferson-Loveday R., Tucker P.G., On the application of LES to seal geometries, Flow, Turbul Combust, Vol. 91(4), pp. 827-848, (2013).

19. Wróblewski W., Dykas S., Bochon K., Rulik S., Optimization of the rotor tip seal with honeycomb land in a gas turbine, 9th Eur Conf Turbomach Fluid Dyn Thermodyn ETC 2011 - Conf Proc, pp. 1-13 (2011).

20. Frączek D., Bochon K., Wróblewski W., Influence of Honeycomb Land Geometry on Seal Performance, Proc ASME Turbo Expo 2016 Power Land, Sea Air, GT2016-57569, pp. 1-11, (2016).

21. Rulik S., Wróblewski W., Frączek D., MetamodelBased Optimization of the Labyrinth Seal, Arch Mech Eng, Vol. 64, pp. 75-91, (2017).

22. Wróblewski W., Frączek D., Marugi K., Leakage reduction by optimisation of the straight - through labyrinth seal with a honeycomb and alternative land configurations, Int J Heat Mass Transf, Vol. 126, pp. 725-739, (2018).

23. Szymanski A., Bochon K., Wróblewski W., Marugi K., Dykas S., Fraczek D., Optimization of the Straight-Through Labyrinth Seal With a Smooth Land, J Eng Gas Turbines Power, Vol. 140(12), pp. 122503-122511, (2018).

24. Frączek D., Wróblewski W., Validation of numerical models for flow simulation in labyrinth seals, J Phys Conf Ser, Vol 760, (2016).

25. Morgan N.R., Wood H.G., Untaroiu A., Numerical Optimization of Leakage By Multifactor Regression of Trapezoidal, Proc ASME Turbo Expo 2015 Power Land, Sea Air, GT2015-43794, pp. 1-10, (2015).

26. Waschka W., Wittig S., Kim S., Influence of High Rotational Speeds on the Heat Transfer and Discharge Coefficients in Labyrinth Seals, $J$ Turbomach, Vol. 114(2), pp. 462-468, (1992).

27. Paolillo R., Moore S., Cloud D., Glahn JA, Impact of Rotational Speed on the Discharge Characteristic of Stepped Labyrinth Seals, Proc ASME Turbo Expo 2007 Power Land, Sea Air, GT2007-28248, pp. 1291-1298, (2007).

28. Schramm V., Willenborg K., Kim S., Wittig S., Influence of a Honeycomb Facing on the Flow Through a Stepped Labyrinth Seal, J Eng Gas Turbines Power Vol. 124(1), pp140-146, (2002). 